\title{
Flora da Bahia: Podocarpaceae
}

\section{Lucas Cardoso Marinho ${ }^{1 *}$, Daniela Santos Carneiro-Torres ${ }^{1, a}$, André Márcio Amorim ${ }^{1,2, b}$, Reyjane Patrícia de Oliveira $^{1, \mathrm{c}}$ \& Ana Maria Giulietti ${ }^{1,3, d}$}

${ }^{1}$ Programa de Pós-graduação em Botânica, Universidade Estadual de Feira de Santana, Feira de Santana, Bahia, Brasil.

${ }^{2}$ Departamento de Ciências Biológicas, Universidade Estadual de Santa Cruz, Ilhéus \& Herbário Centro de Pesquisas do Cacau, CEPEC, Itabuna, Bahia, Brasil.

${ }^{3}$ Instituto Tecnológico Vale Desenvolvimento Sustentável, Belém, Pará, Brasil.

Resumo - É apresentada aqui a flora de Podocarpaceae, única família de gimnospermas nativa na Bahia, Brasil. São reconhecidas duas espécies de Podocarpus: P. lambertii, ocorrendo na região da Chapada Diamantina, e P. sellowii, ocorrendo tanto na Chapada Diamantina quanto nas florestas montanas e submontanas do sul da Bahia. São apresentados chave de identificação, descrições, ilustrações e comentários gerais sobre os táxons.

Palavras-chave adicionais: coníferas, florística, gimnospermas, pinheiro-bravo, Podocarpus, taxonomia.

\begin{abstract}
Flora of Bahia: Podocarpaceae) - The flora of Podocarpaceae, the only family of gymnosperms native to Bahia, Brazil, is presented here. Two species of Podocarpus are recognized: P. lambertii, occurring in the Chapada Diamantina region, and P. sellowii, occurring in the Chapada Diamantina and also in the montane and submontane forests in southern Bahia. Descriptions, identification key, illustrations and general comments on the taxa are presented.
\end{abstract}

Additional key words: conifers, floristics, gymnosperms, pinheiro-bravo, Podocarpus, taxonomy.

\section{PodocARPACEAE}

Árvores ou arbustos dioicos ou raramente monoicos (Saxegothaea Lindl.), autótrofos ou parasitas de raízes (Parasitaxus de Laub.). Folhas simples, inteiras, alternas ou subopostas, raro opostas (Microcachrys Hook. f.), coriáceas, lineares, lanceoladas, aciculares, ovais ou escamiformes, margens inteiras. Microstróbilos terminais ou axilares, solitários ou agrupados, cilíndricos; microsporofilos numerosos, arranjados espiraladamente; microsporângios na face abaxial dos microsporofilos. Cones modificados, geralmente solitários, 1 a várias brácteas, cada qual ou apenas uma com um óvulo ereto ou assimetricamente invertido, as brácteas subsequentes frequentemente coalescendo em um receptáculo seco ou carnoso após a fertilização, então formando um falso arilo (epimácio). Sementes com tegumento externo carnoso e interno lenhoso; embrião com dois cotilédones.

Podocarpaceae possui 176 espécies e 18 gêneros (Cernusak et al. 2011). A maioria dos seus representantes ocorre no hemisfério sul, geralmente em altitudes médias a elevadas (Cernusak et al. 2011). Na Região Neotropical, ocorrem cinco gêneros, dois deles, Retrophyllum C.N.Page e Podocarpus L'Hér. ex Pers., representados no Brasil (Souza 2015).

\footnotetext{
*Autor para correspondência: 1cmarinho1@gmail.com;

adscarneiro@hotmail.com; bamorim.uesc@gmail.com;

'rpatricia@uefs.br; dana.giulietti@vale.org

Editor responsável: Alessandro Rapini

Submetido: 30 maio 2016; aceito: 29 jul. 2016

Publicação eletrônica: 12 ago. 2016; versão final: 19 ago. 2016
}

Podocarpus L'Hér. ex Pers.

Árvores, arvoretas ou arbustos dioicos. Folhas alternas a subopostas, lineares a ovais, patentes, ápice agudo a mucronado, com uma nervura central e canais resiníferos. Microstróbilos axilares, solitários ou agrupados, sésseis a subsésseis; escamas estéreis na base. Cones pedunculados; epimácio formado por 2 ou 3 brácteas. Sementes orbiculares a elipsoides, ápice apiculado ou arredondado.

Podocarpus ocorre em todas as Regiões do Brasil, representado por oito (Souza 2015) das suas 31 (Dalling et al. 2011) espécies. Duas espécies do gênero foram reconhecidas para a Bahia, $P$. lambertii e $P$. sellowii, ambas ocorrendo preferencialmente em áreas de altitude, a primeira restrita à Chapada Diamantina e a segunda ocorrendo também nas florestas montanas e submontanas do sul da Bahia.

\section{Chave para as espécies}

1. Folhas 2,2-4 × 0,3-0,5 cm, elípticas a lineares; escamas da gema apical $0,6-1,5 \mathrm{~mm}$ compr., triangulares a largamente triangulares, ápice obtuso, raro agudo; microstróbilos 6-13 mm compr., 2 ou 3 por axila foliar

1. P. lambertii

1'. Folhas 3,2-19 × 0,7-2,1 cm, elípticas a oblongas; escamas da gema apical 2-4 mm compr., triangularlanceoladas, ápice agudo; microstróbilos 10-25 mm compr., 1 por axila foliar 2. P. sellowii

1. Podocarpus lambertii Klotzsch ex Endl., Syn. Conif.: 211. 1847.

Figuras 1 e $2 \mathrm{~A}-\mathrm{E}$.

Árvores ou arvoretas 1,5-8 m alt.; ramos glabros; escamas da gema apical $0,6-1,5 \mathrm{~mm}$ compr., triangulares a largamente triangulares, ápice obtuso, 
raro agudo. Folhas $2,2-4 \times 0,3-0,5 \mathrm{~cm}$, elípticas a lineares, ápice agudo a arredondado, margens fortemente revolutas, base atenuada, glabras em ambas as faces, sésseis. Microstróbilos 6-13 mm compr., 2 ou 3 por axila foliar, amarelo-esverdeados, subsésseis, agrupados em um pedúnculo de 3-8,2 $\mathrm{mm}$ compr., glabro; escamas basais 1,5-2 $\mathrm{mm}$ compr., coriáceas, naviculares, ápice agudo a acuminado, margens erosas, base truncada, glabras; microsporofilos 7-1 $\times 0,8-1$ $\mathrm{mm}$, triangular-lanceolados, glabros, projeção apical deltoide na face interna $2-3 \mathrm{~mm}$ compr.; microsporângios 2, 7-1 × 0,4-0,5 $\mathrm{mm}$, elípticos. Cones 1 ou 2 por axila foliar; pedúnculo $0,5-3,2 \mathrm{~mm}$ compr., glabro; epimácio 3-6 $\mathrm{mm}$ compr., azulesverdeado a glauco. Sementes 3,5-5 mm compr., orbiculares, ápice arredondado, verdes a glaucas.

Podocarpus lambertii é registrada em todos os estados das Regiões Sul e Sudeste, além da Bahia (Souza 2015). É uma árvore de pequeno porte em formações abertas, mas de grande porte nas florestas do sul do país (Carvalho 2004). Souza (2010) e Dalling et al. (2011) consideraram P. lambertii endêmica do Brasil, apesar de Martínez-Crovetto (1963) haver indicado a espécie para a Argentina. D6 e F6: campo rupestre, 1200 a $1800 \mathrm{~m}$ s.n.m., geralmente crescendo entre capões estreitos e fendas de rochas. Coletada fértil em junho e entre novembro e abril.

Material selecionado - Abaíra, Catolés de Cima, 13ำ' $16^{\prime}$, 41 ${ }^{\circ} 54^{\prime}$ 'W, 9 jan. 1999 (ㅇ), R.M. Harley et al. 53433 (HUEFS);

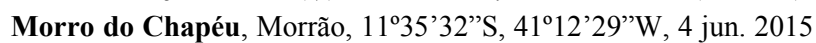
(ठ) ), L.P. Queiroz et al. 16138 (HUEFS); Rio de Contas, Serra da Mesa, 1321'55”'S, 4153'16”'W, dez. 2008 (ð’), F.H.F. Nascimento 648 (HUEFS); Rio do Pires, Campo do Cigano, 1315'43"S, 415'29”'W, 1 abr. 2000 (ㅇ), , F.H.F. Nascimento 364 (HUEFS).

Os indivíduos de Podocarpus lambertii são semelhantes aos de $P$. sellowii na Chapada Diamantina,

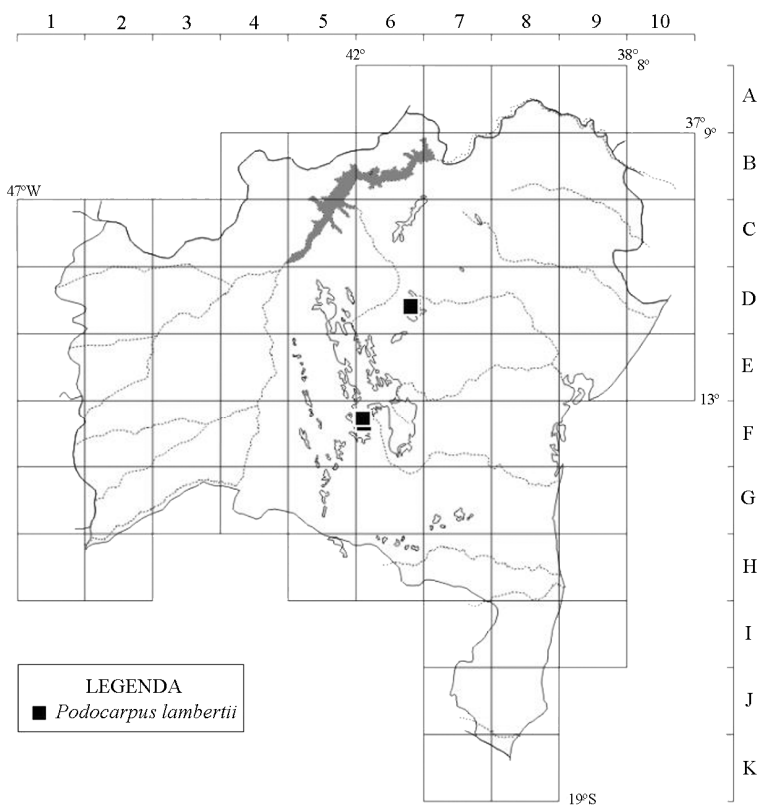

Figura 1. Distribuição geográfica de Podocarpus lambertii no estado da Bahia. fazendo com que essas espécies possam ser confundidas. Em seus extremos, alguns caracteres, como o comprimento das folhas e dos microstróbilos, se sobrepõem. No entanto, o número de microstróbilos por axila foliar é determinante para a distingui-las. A largura da folha e, consequentemente, seu formato também podem ajudar na identificação dessas espécies, principalmente quando as amostras estiverem estéreis.

\section{Podocarpus sellowii Klotzsch ex Endl., Syn. Conif.:} 209. 1847

Figuras 2F-J, 3 e 4.

Árvores ou arvoretas 2-6(-30) $\mathrm{m}$ alt.; ramos glabros; escamas da gema apical 2-4 $\mathrm{mm}$ compr., triangular-lanceoladas, ápice agudo. Folhas 3,2-19 $\times$ 0,7-2,1 cm, elípticas a oblongas, ápice agudo a arredondado, margens revolutas, base atenuada, glabras em ambas as faces, sésseis. Microstróbilos 10-25 mm compr., 1 por axila foliar, alvo-amarelados, sésseis; escamas basais 1,8-2 $\mathrm{mm}$ compr., coriáceas, naviculares, ápice agudo, margens erosas, base truncada, glabras; microsporofilos $0,8-1,2 \times 1-1,2$ $\mathrm{mm}$, triangular-lanceolados, glabros, projeção apical deltoide na face interna ca. $1 \mathrm{~mm}$ compr.; microsporângios $2,0,8-1,2 \times 0,5-0,6 \mathrm{~mm}$, elípticos. Cones 1 por axila foliar; pedúnculo $4-7 \mathrm{~mm}$ compr., glabro; epimácio 3,5-5 $\mathrm{mm}$ compr., verde-escuro. Sementes 3-7 $\mathrm{mm}$ compr., orbiculares, ápice arredondado, verde-claras.

Podocarpus sellowii é amplamente distribuída no Brasil, ocorrendo em todos os estados das Regiões Centro-Oeste, Sul e Sudeste, além do Acre, Alagoas, Bahia, Ceará, Pará, Pernambuco, Rondônia e Sergipe (Souza 2015). D7, E6 e F6: campo rupestre; F8, G7, G8, H8 e I7: floresta ombrófila densa submontana e montana, (50-)700 a 1800 m s.n.m. Coletada fértil entre outubro e abril.

Material selecionado - Abaíra, Tijuquinho, $13^{\circ} 16^{\prime} \mathrm{S}$, $41^{\circ} 54^{\prime}$ W, 8 jan. 1992 (ㅇ), R.M. Harley et al. 51221 (CEPEC, HUEFS); Arataca, Parque Nacional Serra das Lontras, Serra Fina, $15^{\circ} 11^{\prime} 50^{\prime \prime} \mathrm{S}, 39^{\circ} 23^{\prime} 28^{\prime \prime} \mathrm{W}, 8$ nov. 2008 (est.), J.G. Jardim et al. 5435 (CEPEC); Boa Nova, Parque Nacional de Boa Nova, 14²4'45"S, 4007'46”'W, 7 jan. 2013 (est.), L.Y.S. Aona et al. 1974 (HUEFS, HURB); Itagimirim, Parque Nacional Alto Cariri, 162'13"S, 4003'16”'W, 8 fev. 2006 (est.), A.M. Amorim et al. 5566 (CEPEC, SPF); Lençóis, Chapadinha, 12²7’01”'S,

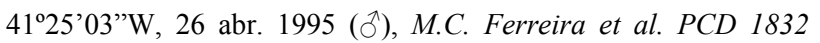
(ALCB, CEPEC, HUEFS); Miguel Calmon, Piemonte da

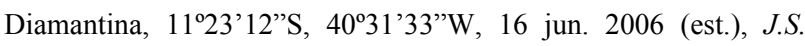
Santos et al. 100 (ALCB); Mucugê, Reserva do Projeto Sempre-

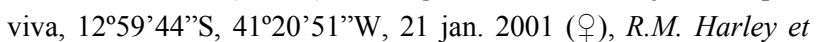
al. 54068 (HUEFS); Una, Reserva Biológica de Una, Subparcela PELD 170/180, 15²0'23”'S, 3907'56”W, ago. 2015 (est.), R.B. Oliveira et al. 466 (CEPEC); Uruçuca, Parque Estadual da Serra do Conduru, 14¹9'54"S, 3901'45”'W, 12 dez. 2015 (est.), A.M. Amorim et al. 10003 (CEPEC); Wenceslau Guimarães, Estação Ecológica Estadual Nova Esperança, Pico do Urubu, 1335'34"S,

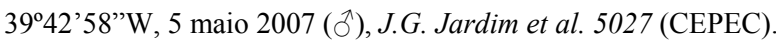




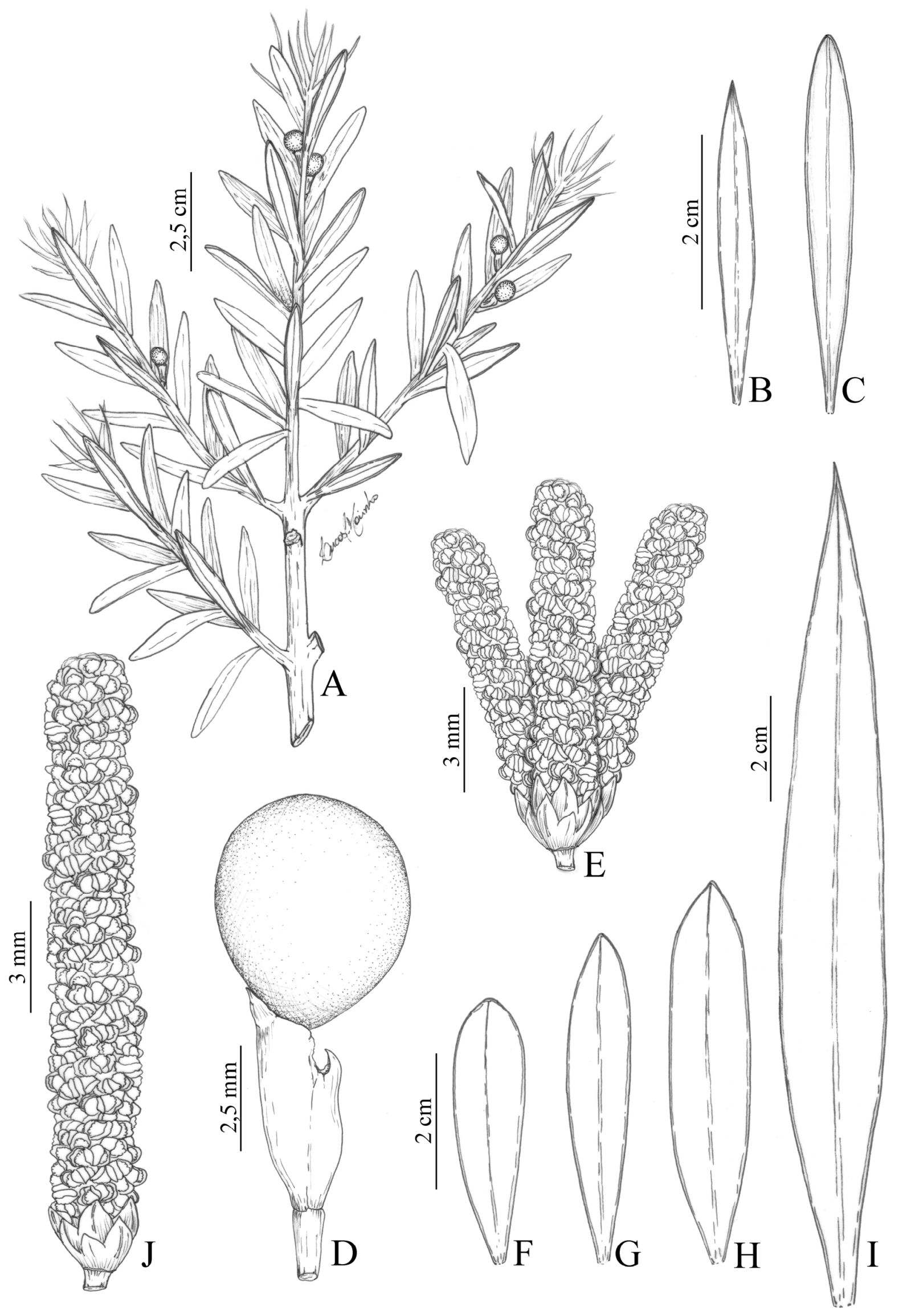

Figura 2. A-E. Podocarpus lambertii: A- ramo fértil (planta ९); B-C- variação foliar, vista abaxial; D- cone, com pedúnculo na base, receptáculo formado por duas brácteas, e um óvulo no ápice; E- pedúnculo com três microstróbilos. F-J. P. sellowii: F-I- variação foliar, vista abaxial; J- microstróbilo. (A, C, D- Nascimento 571; B- França 3451; E- França 5336; F- Harley 54068; G- Faustino 54; H- Stannard 52824; I- Aona 1974; J- Ferreira PCD 1832). 


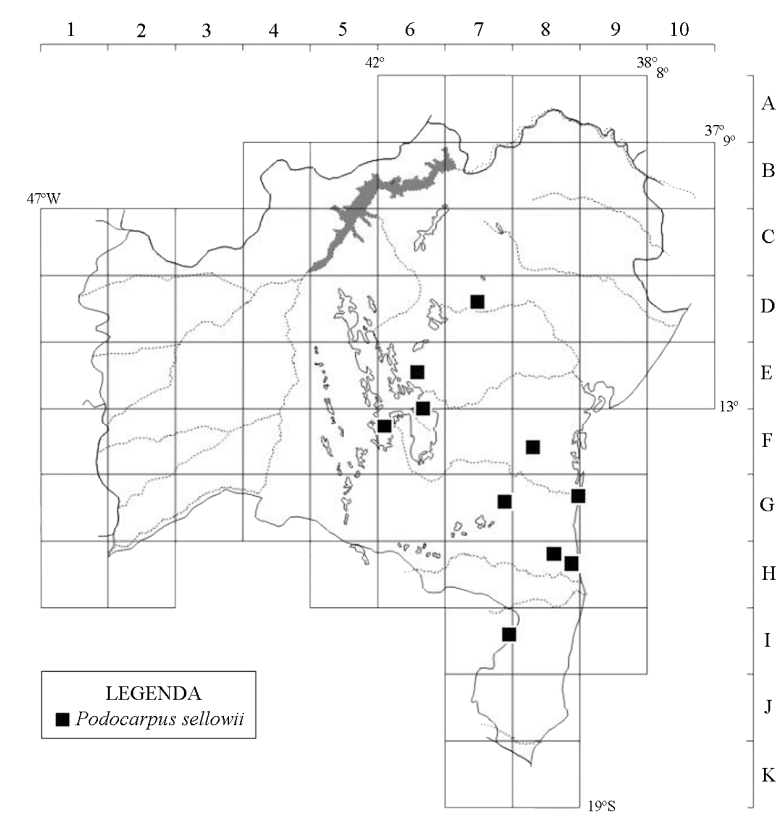

Figura 3. Distribuição geográfica de Podocarpus sellowii no estado da Bahia.

Podocarpus sellowii apresenta grande variação nas estruturas vegetativas e na disposição dos microstróbilos, também notada nas populações de São Paulo (Garcia 2002) e observadas na ampla variação foliar de sua coleção-tipo (Sellow 301), examinada por meio de arquivos digitais dos herbários BM, E, F, HAL, K-3 arquivos, P-4 arquivos e UC. De Laubenfels (1985) reconheceu que $P$. sellowii pode apresentar de 3 a 6 microstróbilos por pedúnculo, mas também 1 ou 2 microstróbilos por axila, e indicou a presença de características transicionais entre as seções $P$. sect. Capitulatis de Laub. e $P$. sect. Lanceolatis de Laub., como os microstróbilos solitários e escamas da gema apical alongadas. A grande variação morfológica de $P$. sellowii está bem representada na Bahia, com acentuada discrepância entre os materiais provenientes do sul do estado (Figura 2I) e os da Chapada Diamantina (Figura 2F-H).

\section{AGRADECIMENTOS}

Ao CNPq, pela bolsa de Doutorado concedida a LCM e pelas bolsas de Produtividade em Pesquisa concedidas a AMA (PQ-2), AMG (PQ-Senior) e RPO (PQ-1D). À FAPESB, pelo apoio ao Projeto Flora da Bahia (APR0162/2007); ao CNPq, pelo apoio ao PROTAX (562278/2010-9), PPBIO Semiárido (472574/2012-4) e Mata Atlântica (457483/2012-1) e ao projeto Flora da Bahia (483909/2012-4). A Eudes Barletta, pelo auxílio na fase inicial do trabalho.

\section{REFERÊNCIAS}

Carvalho, P.E.R. 2004. Pinheiro-Bravo, Podocarpus lambertii. Circular Técnica - Embrapa Florestas 95: 1-9.

Cernusak, L.A.; Adie, H.; Bellingham, P.J.; Biffin, E.; Brodribb, T.J.; Coomes, D.A.; Dalling, J.W.; Dickie, I.A.; Enright, N.J.; Kitayama, K.; Ladd, P.G.; Lambers, H.; Lawes, M.J.; Lusk, C.H.; Morley, R.J. \& Turner, B.L. 2011. Podocarpaceae in tropical forests: a synthesis. In: B.L. Turner \& L.A. Cernusak (eds), Ecology of the Podocarpaceae in Tropical Forests. Vol. 95. Smithsonian Institution Scholarly Press, Washington, p. 189-195.

Dalling, J.W.; Barkan, P.; Bellingham, P.J.; Healey, J.R. \& Tanner, E.V.J. 2011. Ecology and distribution of neotropical Podocarpaceae in tropical forests: a synthesis. In: B.L. Turner \& L.A. Cernusak (eds), Ecology of the Podocarpaceae in Tropical Forests. Vol. 95. Smithsonian Institution Scholarly Press, Washington, p. 43-56.
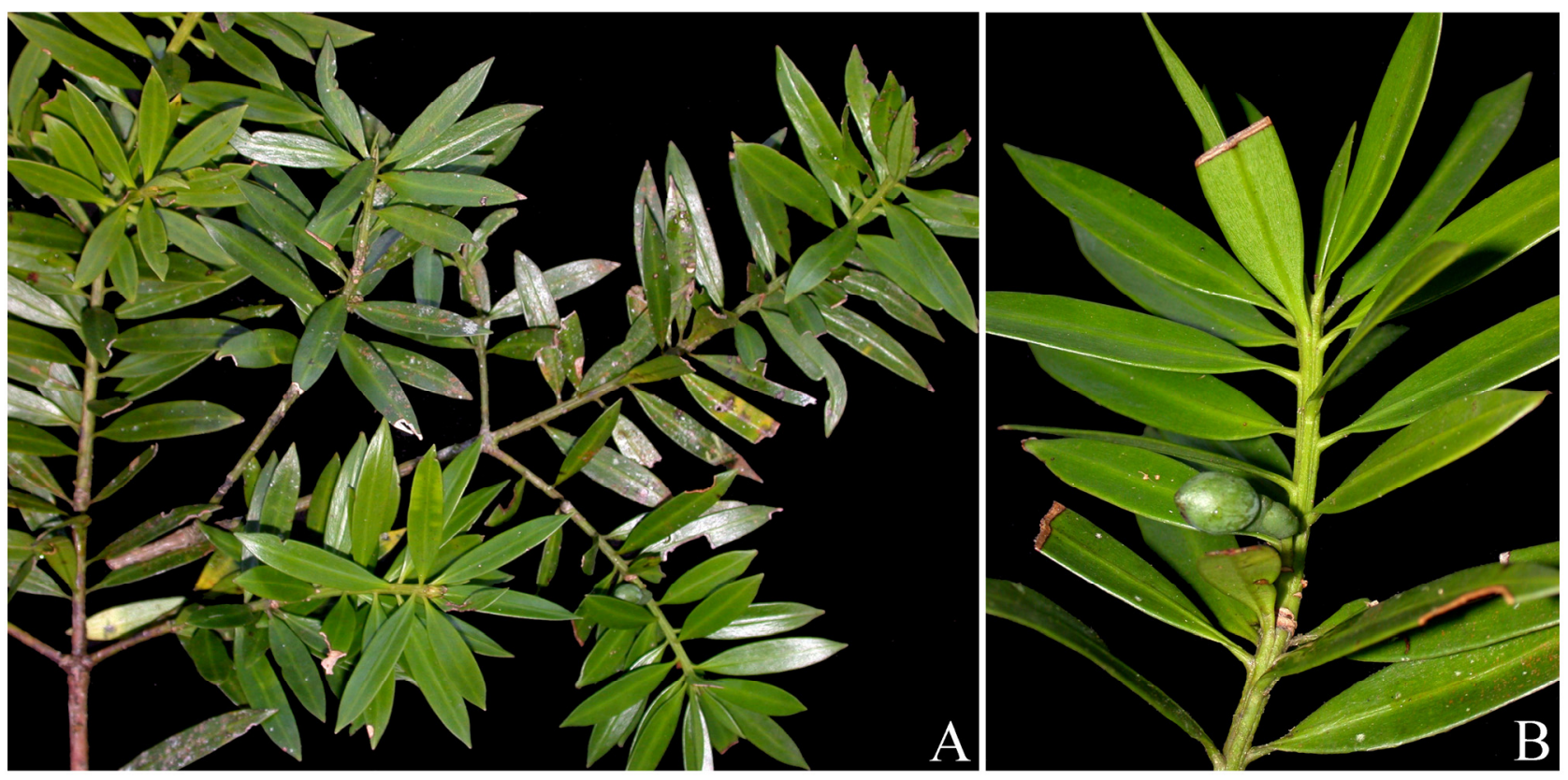

Figura 4. A-B. Podocarpus sellowii: A- ramo fértil (planta + ); B- detalhe do ramo, evidenciando o cone (Amorim 5566; fotos: A.M. Amorim). 
De Laubenfels, D.J. 1985. A taxonomic revision of the genus Podocarpus. Blumea 30: 251-278.

Garcia, R.J.F. 2002. Podocarpaceae. In: M.G.L. Wanderley, G.J. Shepherd \& A.M. Giulietti (eds), Flora Fanerogâmica do Estado de São Paulo. Vol. 2. Hucitec, São Paulo, p. 2-4.

Martínez-Crovetto, R. 1963. Esquema fitogeográfico de la Provincia de Misiones (República Argentina). Bonplandia 1: 171-223.
Souza, V.C. 2010. Introdução: as gimnospermas do Brasil. In: R.C. Forzza et al. (orgs). Catálogo de Plantas e Fungos do Brasil. Vol. 1. Andrea Jakobsson Estúdio, Instituto de Pesquisa Jardim Botânico do Rio de Janeiro, Rio de Janeiro, p. 75-77.

Souza, V.C. 2015. Podocarpaceae. In: Lista de Espécies da Flora do Brasil. Jardim Botânico do Rio de Janeiro. Disponível em http://floradobrasil.jbrj.gov.br/jabot/floradobrasil/FB258; acesso em 25 jan. 2016

\section{LISTA DE EXSICATAS}

Amorim, A.M. 5566, 8702, 10003 (2); Aona, L.Y.S. 1974 (2); Bautista, H.P. 397, PCD 3192 (1); Costa, A.L. s.n. HUEFS 8738 (1); Faustino, T.C. 54 (2); Ferreira, M.C. PCD 1832 (2); França, F. 3451, 5336 (1); Ganev, W. 1926 (1); Gasson, P. PCD 5942 (1); Giulietti, A.M. 1931 (2); Guedes, M.L. 14543, 19841 (1); Hage, J.L. 2329 (1); Harley, R.M. 22780, 25768, 26658 (1), 50620,51221 (2), 52037, 53433 (1), 54068 (2); PCD 3179, PCD 4293, 19307 (1); Jardim, J.G. 5027, 5435 (2); Lima, H.C. 3895 (1); Mori, S.A. 14461 (1); Nascimento, F.H.F. 364, 569, 571, 591, 648 (1); Nogueira, T. 44 (2); Oliveira, R.B. 466 (2); Pinto, G.C.P. 113 (1); Queiroz, L.P. 4033 , 4285, 13312, 16138 (1); Roque, N. 2981 (2); Santos, J.S. 100 (2). Sellow, F. 301 (2). Stannard, B. 50828 (1), 52824 (2). 